\title{
Baumol's cost disease and the sustainability of the welfare state
}

Kreiner, Claus Thustrup; Andersen, Torben M.

Publication date:

2015

Document version

Peer reviewed version

Citation for published version (APA):

Kreiner, C. T., \& Andersen, T. M. (2015). Baumol's cost disease and the sustainability of the welfare state. EPRU Working Paper Series Vol. 2015 No. 2 
Economic Policy Research Unit

Department of Economics

University of Copenhagen

$\emptyset$ ster Farimagsgade 5, Building 26

DK-1353 Copenhagen $K$

DENMARK

Tel: (+45) 35324411

Fax: (+45) 35324444

Web: http://www.econ.ku.dk/epru/

\section{Baumol's cost disease and the sustainability of the welfare state}

Torben Andersen, Claus Thustrup Kreiner 


\title{
Baumol's cost disease and the sustainability of the welfare state*
}

\author{
Torben M. Andersen \\ Aarhus University \\ IZA, CESifo and CEPR
}

\author{
Claus T. Kreiner \\ University of Copenhagen \\ EPRU, CESifo and CEPR
}

February 2015

\begin{abstract}
If productivity increases more slowly for services than for manufactured goods then services suffer from Baumol's cost disease and tend to become relatively more costly over time. Since the welfare state in all countries is an important supplier of tax financed services, this translates into a financial pressure which seems to leave policymakers with a trilemma; increase taxes (and hence tax distortions), cut spending or redistribute less. Under the assumptions underlying Baumol's cost disease, we show that these dismal implications are not warranted. The welfare state is sustainable and Baumol growth leaves scope for Pareto improvements.
\end{abstract}

*We are grateful to Peter Birch Sørensen for comments on an earlier draft. Contact info: ctk@econ.ku.dk (Claus T. Kreiner) and tandersen@econ.au.dk (Torben M. Andersen). 
An economic specter haunts the democratic governments of the world's most prosperous economies. The rising cost of health care and education casts a shadow over virtually any election......ever more of gross national product will have to be channeled through the public sector, with all the problems we know that to entail (Baumol, 1993, p. 17).

\section{Introduction}

This paper analyses implications of Baumol's cost disease for the sustainability of the welfare state. Baumol (1967) raised the issue of how society would develop if there are ongoing productivity increases in the production of manufactured commodities and no (or lower) productivity increases in the production of services. ${ }^{1}$ If wage increases are the same across sectors, it follows that the cost or price of services increases relative to manufactured commodities. A mechanism known as Baumol's cost disease. Baumol predicted an ever declining employment level in manufacturing, increasing employment in the service sector, and eventually a stagnant economy. Although the Baumol cost disease applies to services in general, and not whether they are provided by the private or the public sector, a number of authors have pointed to the particular difficulties it raises for tax financed service provision. Baumol (1993) predicts that an ever increasing share of the gross domestic product will be absorbed by the public sector, and thus eventually lead to a tax rate in conflict with the Laffer bound. Similar arguments are made in e.g. Lindbeck (2006) and van der Ploeg (2007).

Empirical evidence confirms Baumol's productivity assumption and the implied structural changes. Empirical analyses show that services in general tend to have lower productivity growth than other goods and therefore service prices tend to grow faster, see e.g. Nordhaus (2008). Structural changes leading to a declining employment share in manufacturing sectors (in a broad sense including both primary and secondary sectors) and increasing employment shares in private and public services are observed for all OECD countries. It is also noteworthy that assessments of fiscal sustainability commonly point to Baumol's cost disease as an important expenditure driver, see e.g. IMF

\footnotetext{
${ }^{1}$ See also Baumol and Bowen (1966), Baumol (1993) and Baumol et al. (2012).
} 
(2012) and European Commission (2013) as well as a long list of specific country studies including Bates and Santerre (2013) on the US, Office of Budget Responsibility (2013) on the UK, New Zealand Treasury (2012) on New Zealand, DREAM (2014) on Denmark, and Regeringen (2013) on Sweden.

The implications of Baumol's cost disease seem to be dismal, stagnating economies and unsustainable public sectors. The stagnation implication has been reputed. Even accepting the premise of differences in productivity growth between manufactured goods and services as well as increasing employment shares in services, it does not necessarily follow that economies will stagnate. Ngai and Pissarides (2007) show that both facts are consistent with ongoing growth when accounting for capital goods needed in both manufacturing and service production.

We consider the implications of Baumol cost disease for the public sector or the welfare state in more general terms. We interpret the welfare state broadly in the sense of tax financed provision of services (including education, health and care) as well as redistribution. All OECD countries have welfare states although obviously the size and structure differ. If the relative costs of producing publicly provided services grow over time, it seems to bring the welfare state into a financial squeeze leaving a trilemma for policy makers; increase taxes (at the cost of increasing tax distortions), cut spending on services or redistribute less. The latter two choices amount to a retrenchment of the welfare state, which may seem unavoidable because the tax-income ratio has an upper limit (the Laffer rate).

We ask whether the welfare state is sustainable in the sense that the same principles for public provision of services can be maintained, and the same distribution of wellbeing/utility can be attained without comprising public finances. We adopt the original Baumol assumptions on productivity growth and consider the implications for the welfare state under rather general assumptions on individual preferences and the social welfare function. The results of our analysis show that the welfare state is sustainable and, moreover, that Baumol growth leaves room for Pareto improvements.

This result is related to recent work showing that the marginal cost of public funds and the efficiency loss from taxation may be exaggerated when taking marginal tax 
rates at face value and, more generally, pointing to the virtues of generous welfare states, e.g. Blomquist et al. (2010), Kreiner and Verdelin (2012), Jacobs (2013), Jacobs and de Mooij (2014), Barth et al. (2014) and Kleven (2014). In the case considered here, Baumol growth increases the cost of public services and therefore government expenditures but it also changes household income and thereby tax revenue and demand for public services. The effects on household welfare vary across households with different income levels. By using benefit off-setting income taxation (related to the use of the benefit principle or Lindahl pricing in public good provision), we show it is possible to keep utility unchanged at all income levels and increase tax payments without impeding economic efficiency. The increase in tax revenue is always larger than the increase in government expenditures thereby leaving room for Pareto improvements.

The paper is organized as follows: The model featuring Baumol growth and a public sector engaged both in public provision of services and redistribution is set up in Section 2. Sustainability of the welfare state and the basic result on the effect of Baumol growth are provided in Section 3, while Section 4 offers some concluding remarks.

\section{A model of Baumol growth and public policies}

The welfare state provides welfare services and redistributes. To capture both elements we formulate a model in which agents derive utility from a tax-financed public good or service and have different earnings ability giving a motive for redistribution. Ability levels are unobservable by the policy maker, which leads to a classical equity-efficiency trade-off. We consider a two-goods economy with a private good (labelled manufactured good) and a public good/service (labelled service). ${ }^{2}$ The productivity may increase for both types of production, but our main focus will be on the case of Baumol growth where productivity increases more in the production of manufactures than in service production.

\footnotetext{
${ }^{2}$ Since the population size is constant, the public activity may be interpreted as either a collective good or an individualized service like health, care or education.
} 


\subsection{Firms}

The technologies available for production of manufactures $(M)$ and services $(S)$ are given as

$$
\begin{aligned}
Y_{M} & =A_{M} L_{M}, \\
Y_{S} & =A_{S} L_{S},
\end{aligned}
$$

where $L_{i}$ denotes effective input of labour while $A_{i}(i=M, S)$ captures productivity.

We normalize the price of the manufacturing good to one, and let $p_{S}$ denote the price on the service relative to the manufacturing good. The cost per unit of effective labour is denoted $w$ (measured in units of the numeraire good), and assuming that labour is completely mobile between the two sectors implies a uniform wage across the sectors. The first-order conditions for the profit maximization problem of firms become ${ }^{3}$

$$
\begin{aligned}
w & =\partial Y_{M} / \partial L_{M}=A_{M}, \\
\frac{w}{p_{S}} & =\partial Y_{S} / \partial L_{S}=A_{S} .
\end{aligned}
$$

We consider exogenous technological progress:

$$
\begin{aligned}
d A_{M} / A_{M} & =g_{M}, \\
d A_{S} / A_{S} & =g_{S},
\end{aligned}
$$

where Baumol growth is present whenever $g_{M}>g_{S} \geq 0$. From (3) and (4), we have

$$
p_{S}=A_{M} / A_{S} \Rightarrow d p_{S} / p_{S}=g_{M}-g_{S}>0
$$

showing that the Baumol effect makes the service more expensive relative to the manufactured good.

From eqs. (1), (2) and (5), we also have

$$
\frac{p_{S} Y_{S}}{Y_{M}}=\frac{p_{S} A_{S} L_{S}}{A_{M} L_{M}}=\frac{L_{S}}{L_{M}},
$$

showing that the service sector uses a larger fraction of labour if the value of service output increases as a fraction of GDP. ${ }^{4}$

\footnotetext{
${ }^{3}$ Note that with perfect competition and constant returns there is no difference between a situation where the public sector acquires services in the market or is the producer of the service.

${ }^{4}$ The Baumol effect does not necessarily raise the fraction of income used on public services. This
} 


\subsection{Households}

We consider a continuum of households which differ only with respect to abilities $n \in$ $[\underline{n}, \bar{n}]$. Ability levels are fixed and distributed according to the density function $f(n)$ where $f(n) \geq 0$ and $\int_{\underline{n}}^{\bar{n}} f(n) d n=1$. The effective labour input per hour of a type $n$ individual is equal to $n$, implying that the wage per hour becomes

$$
w(n)=w \cdot n=A_{M} n=p_{S} A_{S} n,
$$

where we have used eqs. (3) and (4). Notice that technological progress does not influence the gross wage differential between different types of labour, i.e. $w\left(n^{\prime}\right) / w\left(n^{\prime \prime}\right)=$ $n^{\prime} / n^{\prime \prime}$ is independent of $A_{M}$ and $A_{S}$ for all $n^{\prime}$ and $n^{\prime \prime}$. Thus, Baumol growth does not affect the distribution of relative wages (we do not want to mix up the effects of Baumol growth with the effects of skill-biased technological change).

The households have identical preferences represented by the utility function

$$
u=u(m, s, l)
$$

where $m$ denotes private consumption of the manufactured good, $s$ is consumption of services supplied by the government, and $l$ is hours-of-work. The utility function is twice continuously differentiable, $u_{m}>0, u_{s}>0, u_{l}<0$, and the usual concavity and limit properties apply. The budget constraint of an individual equals

$$
m \leq e-T(e)
$$

where $e \equiv A_{M} n l$ denotes gross earnings (cf. eq. (6)), while $T(e)$ is a non-linear tax function defined over earnings. From eqs. (7), (8) and $l=e /\left(A_{M} n\right)$, we get

$$
\begin{aligned}
M R S_{m e}(e, s, n) & \equiv-\frac{u_{l}(e-T(e), s, l)}{u_{m}(e-T(e), s, l)} \frac{1}{A_{M} n}>0 \\
M R S_{m s}(e, s, n) & \equiv \frac{u_{s}(e-T(e), s, l)}{u_{m}(e-T(e), s, l)}>0
\end{aligned}
$$

which measures the marginal rate of substitution between, respectively, $m$ and $e$, and $m$ and $s$ for a type $n$ individual at the earnings level $e$. A household of type $n$ chooses

requires that the elasticity of substitution between the two types of goods in household demand is below one, cf. also Ngai and Pissarides (2007). We consider a general preference specification and do therefore not impose any restriction on the elasticity of substitution. 
the earnings level $e(n)$ (or, equivalently, $l(n)$ ) and the consumption of manufacturing goods $m(n)$ that maximize (7) subject to (8), for a given level of public services $s$. The first-order condition gives

$$
M R S_{m e}[e(n), s, n]=1-\tau(e(n)),
$$

where $\tau(e(n)) \equiv \partial T(e(n)) / \partial e$ is the marginal tax rate at the income level $e(n)$. We follow the standard approach in optimal income taxation and contract theory and assume that the Spence-Mirrlees single-crossing condition is satisfied (e.g. Salanié, 2003):

$$
\partial M R S_{m e}(e, s, n) / \partial n<0 .
$$

This assumption ensures that the tax system is implementable; i.e., that higher ability individuals always choose higher equilibrium earnings, implying that the government can use income as a signal of the underlying ability.

The indirect utility function of individual $n$ when consumption of the manufactured good and labour supply are chosen optimally is defined as

$$
v(n) \equiv u\left(e(n)-T(e(n)), s, \frac{e(n)}{A_{M} n}\right)
$$

which also implies

$$
v_{n}(n)=-u_{l}(\cdot) \frac{e(n)}{A_{M} n^{2}}>0,
$$

where we have used the Envelope Theorem.

\subsection{Market equilibrium}

Market clearing in the factor market and in the market for the private good implies

$$
L_{M}+L_{S}=\int_{\underline{n}}^{\bar{n}} n l(n) f(n) d n, \quad Y_{M}=\int_{\underline{n}}^{\bar{n}} m(n) f(n) d n .
$$

\subsection{Welfare state/government}

The government decides the level of public service $s=Y_{S}$ and the non-linear tax function $T(\cdot)$, and thereby also the degree of redistribution. Since the government cannot observe ability levels, taxes and transfers depend on observable income, and redistribution of 
income therefore generates an efficiency loss. Note that $T(\cdot)$ may be negative at certain income levels, reflecting that households at these income levels receive net-transfers. The policy choice of the government has to obey the budget constraint

$$
R \equiv \int_{\underline{n}}^{\bar{n}} T(e(n)) f(n) d n-p_{S} \cdot s \geq 0 .
$$

We consider a benevolent government having a social welfare function defined over individual utilities. Our result is general in the sense that we want to show that the welfare state is sustainable under Baumol growth for a large class of social welfare functions determining the level of public service provision and the extent of redistribution. We therefore only impose the mild condition that the policy choice of the government satisfies the Pareto Criterion; i.e., it is impossible to suggest another combination of $s$ and $T(\cdot)$ which would generate a Pareto improvement. Using the Pareto Criterion, it is possible to show that an optimal level of public service satisfies (see Appendix A)

$$
\int_{\underline{n}}^{\bar{n}}\left[M R S_{m s}(e(n), s, n)+\tau(e(n)) \frac{\partial M R S_{m s}(e, s, n) / \partial n}{\partial M R S_{m e}(e, s, n) / \partial n}\right] f(n) d n=p_{S},
$$

which is the modified Samuelson rule that has been derived elsewhere in the Public Finance literature, e.g. Kreiner and Verdelin (2012). The RHS is the marginal rate of transformation of the manufactured good into the public service and the first term in the bracket on the LHS is the aggregate willingness to pay for the public good. These two terms alone constitute the original Samuelson rule, while the second term in the bracket stems from the incomplete information of the government concerning ability levels that give rise to tax distortions. ${ }^{5}$

\section{Sustainability of the welfare state}

In our inquiry into the sustainability of the welfare state, we study whether Baumol growth, after an appropriate adjustment of tax and public expenditure policy, enables a Pareto improvement or, alternatively, that a Pareto worsening is unavoidable. For

\footnotetext{
${ }^{5}$ The denominator in the second term is negative due to the single-crossing condition (12), and the sign of the tax distortion effect is therefore determined by $\partial \mathrm{MRS}_{m s} / \partial n$, which can be both positive and negative. In the special case of weak separability, where $u(m, s, l)=\tilde{u}(h(m, s), l)$, the tax distortion effect is zero, and the original Samuelson rule applies, see e.g. Christiansen (1981) and Boadway and Keen (1993).
} 
this agenda to make sense, we assume that the initial equilibrium is Pareto optimal implying the public service consumption satisfies the modified Samuelson rule (16). Thus, we define the welfare state to be sustainable under Baumol growth if it is possible to satisfy the demand for the public service according to the modified Samuelson rule and at the same time maintain an unchanged distributional profile of utility without violating the government budget constraint. With this definition, we have

Proposition 1 ( $i$ ) The welfare state is sustainable under Baumol growth; i.e., it is possible to satisfy service demand according to the modified Samuelson rule (16) and maintain an unchanged distribution of well-being $v(n)$ for all ability levels $n$ without violating the government budget constraint (15). (ii) It is always possible to obtain Pareto improvements from Baumol growth.

Proof: See Appendix B.

The proof of the proposition shows that it is possible under Baumol growth to keep everybody at their original utility level by an appropriate adjustment of the tax function, to maintain a supply of welfare services in accordance with the modified Samuelson rule (16), and at the same time obtain an increase in government revenue. Hence, the viability of the welfare state is not at stake, and the policy makers obtain degrees of freedom since the extra government revenue may, for example, be used to raise the wellbeing of everybody through a lump sum grant (this may reduce government revenue through an income effect on labour supply, but this effect would be of second order). This would give a Pareto improvement without increasing any measure of the inequality of well-being (on the contrary inequality would be reduced by most measures).

It is worth emphasizing that the above result is derived under reasonably weak assumptions; e.g., we have not imposed any strong assumptions on individual preferences, such as weak separability as often done in related literature, nor on the social welfare function. 


\section{Concluding remarks}

Baumol growth or Baumol's cost disease is widely perceived to lead the welfare state into the trilemma of either having to increase taxes or make retrenchment of the welfare state by cutting spending on services or redistribute less. In our analysis, this view turns out to be wrong; it is possible to maintain principles for public provision of services and an unchanged distributional profile of well-being. Actually, Baumol growth leaves degrees of freedom by generating an increase in government revenue that creates scope for a Pareto improvement.

Our analysis relies on the flexibility of non-linear income tax schemes, which makes it possible to adjust tax payments at any income level to match changes in willingness to pay for public service, i.e. the benefit principle may be applied. It may be argued that this assumption - also underlying the Mirrleesian optimal income tax frameworkrequires more flexibility in income taxation than what is actually possible, e.g. Slemrod and Yitzhaki (2001). While we recognize there may be limits on the flexibility of the tax system in practice, the point of our analysis is to show that Baumol growth does not inevitably lead to unsustainability of the welfare state.

We have adopted a standard Mirrleesian type setting with homogenous preferences and heterogeneity in innate abilities. A model with heterogeneity along both dimensions would be considerably more complex. In such a setting, it would be impossible to derive results based solely on the Pareto criteria because willingness-to-pay for public services would differ across households with the same level of income and therefore the same tax payment.

Our second-best analysis includes distortions in labor supply and in the composition of consumption between private sector goods and public sector goods. Both distortions are related to the revenue side of the public sector and vanishes in the special case of a perfectly inelastic labour supply. Another potential challenge may be on the expenditure side of the public sector where the optimal allocation of resources may be hampered by the lack of clear price signals, competitive pressure etc. implying a larger public sector may be detrimental to economic efficiency, e.g. Sørensen (2015). 


\section{A Derivation of equation (16)}

Our derivation of the modified Samuelson rule follows the approach in Kreiner and Verdelin (2012). We consider a small (marginal) increase in $s$ and a change in the tax function $T(\cdot)$ that keeps the utility level $v(n)$ fixed at all ability levels $n$. If such a change raises government revenue, then it is possible to make a Pareto improvement, implying that the initial level of $s$ is socially suboptimal. If, on the other hand, government revenue decreases, then a Pareto improvement can be achieved by decreasing $s$. Hence, if the level of public service is set optimally, a Pareto improvement is not possible.

From the government budget constraint (15), we have

$$
d R \equiv \int_{\underline{n}}^{\bar{n}}(d T(e(n))+\tau(e(n)) d e(n)) f(n) d n-p_{S} \cdot d s
$$

where $d T(e(n))$ is the mechanical change in tax burden at the income level $e(n)$ while $\tau(e(n)) d e(n)$ is the change in government revenue due to behavioural responses.

Unchanged utility at all ability levels implies from eqs. (13) and (14) that the change in the allocation satisfies

$$
\begin{aligned}
d v(n) & =u_{m} d m+u_{s} d s+u_{l} \frac{d e(n)}{A_{M} n}=0 \\
d v_{n}(n) & =-\left[u_{m l} d m+u_{s l} d s+u_{l l} \frac{d e(n)}{A_{M} n}\right] \frac{e(n)}{A_{M} n^{2}}-u_{l} \frac{d e(n)}{A_{M} n^{2}}=0,
\end{aligned}
$$

for all $n .{ }^{6}$ By isolating $d m$ in the first of these equations and substituting the result into the second equation, we obtain

$$
d e(n)=\left[\frac{u_{s l}-u_{m l} \frac{u_{s}}{u_{m}}}{u_{m l} \frac{u_{l}}{u_{m}} \frac{1}{A_{M} n}-u_{l l} \frac{1}{A_{M} n}-u_{l} \frac{1}{e}}\right] d s .
$$

From eqs. (9) and (10), we have

$$
\begin{aligned}
\frac{\partial M R S_{m s}(e, s, n)}{\partial n} & =-\frac{e}{u_{m} A_{M} n^{2}}\left[u_{s l}-u_{m l} \frac{u_{s}}{u_{m}}\right] \\
\frac{\partial M R S_{m e}(e, s, n)}{\partial n} & =-\frac{e}{u_{m} A_{M} n^{2}}\left[u_{m l} \frac{u_{l}}{u_{m}} \frac{1}{A_{M} n}-u_{l l} \frac{1}{A_{M} n}-\frac{u_{l}}{e}\right] .
\end{aligned}
$$

By inserting these two derivatives in (A-4), we obtain

$$
d e(n)=\frac{\partial M R S_{m s}(e, s, n) / \partial n}{\partial M R S_{m e}(e, s, n) / \partial n} d s
$$

\footnotetext{
${ }^{6}$ These two conditions also ensure that the post-reform allocation is incentive compatible (see Kreiner and Verdelin, 2012).
} 
The household budget constraint $m=e-T(e)$ implies that $d m=(1-\tau) d e-d T(e)$.

This expression and the first order condition (11) enable us to write condition (A-2) as

$$
d T(e(n))=\frac{u_{s}(\cdot)}{u_{m}(\cdot)} d s=M R S_{m s}(e, s, n) \cdot d s .
$$

This equation shows that the increase in the tax burden of an individual with earnings $e$ is exactly equal to the extra benefit from the expansion of government consumption.

By inserting eqs. (A-5) and (A-6) into (A-1), we obtain

$$
\frac{d R}{d s}=\int_{\underline{n}}^{\bar{n}}\left(M R S_{m s}(e(n), n)+\tau(e(n)) \frac{\partial M R S_{m s}(e, s, n) / \partial n}{\partial M R S_{m e}(e, s, n) / \partial n}\right) f(n) d n-p_{S} .
$$

If $d R / d s>0$, then it is possible to make a Pareto improvement by increasing $s$, and if $d R / d s<0$, then it is possible to make a Pareto improvement by reducing $s$. Hence, a Pareto optimum is characterized by $d R / d s=0$, which gives the result in eq. (16).

\section{B Proof of Proposition 1}

We use a dual approach to prove the proposition. Technological progress raises wages and changes the relative size of the public sector. To maintain an unchanged distributional profile, we consider an adjustment in the non-linear income tax that keeps everybody at the pre-change utility level. At the same time public provision should satisfy (16). If the increase in tax revenue is larger than the extra costs on governmentprovided services, then the government is able to fulfil all requirements in the definition of sustainability. According to the dual approach, at every income level both the direct change to the tax burden and the change in the marginal tax rate are determined endogenously by the requirement that the utility of all individuals is unchanged (the benefit principle), implying that $v(n)$ and $v_{n}(n)$ are fixed. Following a change in productivity and a change in public service, we consider a change in the tax function $T(\cdot)$ such that for all $n$, we have $d v(n)=0$ and $d v_{n}(n)=0$. Using (13) and (14), these two conditions give

$$
d v(n)=u_{m} d m+u_{s} d s+u_{l} \frac{d e}{A_{M} n}-\frac{u_{l} e}{A_{M} n} g_{M}=0
$$




$$
\begin{aligned}
d v_{n}(n)= & -u_{m l} \frac{e}{A_{M} n^{2}} d m-u_{s l} \frac{e}{A_{M} n^{2}} d s-u_{l} \frac{d e}{A_{M} n^{2}}-u_{l l} \frac{e \cdot d e}{A_{M}^{2} n^{3}} \\
& +\frac{u_{l} e}{A_{M} n^{2}} g_{M}+u_{l l} \frac{e^{2}}{A_{M}^{2} n^{3}} g_{M}=0 .
\end{aligned}
$$

From (B-7), we get

$$
d m=\frac{u_{l}}{u_{m}} \frac{e}{A_{M} n} g_{M}-\frac{u_{l}}{u_{m}} \frac{e}{A_{M} n} \frac{d e}{e}-\frac{u_{s}}{u_{m}} d s
$$

and from (B-8), we have

$$
0=-u_{m l} d m-u_{s l} d s-\left[u_{l}+u_{l l} \frac{e}{A_{M} n}\right] \frac{d e}{e}+\left[u_{l}+u_{l l} \frac{e}{A_{M} n}\right] g_{M} .
$$

After substituting $d m$ from eq. (B-9) into this expression, we obtain

$$
d e=\frac{\frac{u_{m l} u_{s}}{u_{m}}-u_{s l}}{\frac{u_{l}}{e}+u_{l l} \frac{1}{A_{M} n}-\frac{u_{m l} u_{l}}{u_{m}} \frac{1}{A_{M} n}} d s+e \cdot g_{M} .
$$

From eqs. (9) and (10), we have

$$
\begin{aligned}
\frac{\partial M R S_{m s}(e, s, n)}{\partial n} & =\frac{e}{u_{m} A_{M} n^{2}}\left[u_{m l} \frac{u_{s}}{u_{m}}-u_{s l}\right] \\
\frac{\partial M R S_{m e}(e, s, n)}{\partial n} & =\frac{e}{u_{m} A_{M} n^{2}}\left[\frac{u_{l}}{e}+u_{l l} \frac{1}{A_{M} n}-\frac{u_{m l} u_{l}}{u_{m}} \frac{1}{A_{M} n}\right] .
\end{aligned}
$$

By inserting these two derivatives in (B-10), we obtain

$$
d e=\frac{\partial M R S_{m s}(e, s, n) / \partial n}{\partial M R S_{m e}(e, s, n) / \partial n} d s+e \cdot g_{M}
$$

Insertion of this expression into (B-7) gives

$$
d m=-\frac{u_{s}}{u_{m}} d s-\frac{u_{l}}{u_{m}} \frac{1}{A_{M} n} \frac{\partial M R S_{m s}(e, s, n) / \partial n}{\partial M R S_{m e}(e, s, n) / \partial n} d s .
$$

The household budget constraint (8) implies

$$
d m=(1-\tau) d e-d T(e)
$$

where $d T(e)$ denotes the change in the total tax burden at the earnings level $e$. After using eqs. (B-11) and (B-12) to substitute for de and $d m$, we obtain

$$
\begin{aligned}
d T(e) & =\left(1-\tau+\frac{u_{l}}{u_{m}} \frac{1}{A_{M} n}\right) \frac{\partial M R S_{m s}(\cdot) / \partial n}{\partial M R S_{m e}(\cdot) / \partial n} d s+(1-\tau) e \cdot g_{M}+\frac{u_{s}}{u_{m}} d s \\
& =(1-\tau) e \cdot g_{M}+\frac{u_{s}}{u_{m}} d s,
\end{aligned}
$$


where the last equality follows from the optimum condition of the household (11). The above expression measures the compensating increase in the tax burden of a type $n$ individual compared to the existing system; i.e., the benefit principle implies that the tax function is adjusted to capture the benefits of individual $n$ from a higher public service and a higher productivity. If the net effect on government revenue of the changes in productivity and public service and the required change in taxation is positive, then the welfare state is sustainable. In order to show that this is the case, we differentiate the government revenue (15). This gives

$$
d R=\int_{\underline{n}}^{\bar{n}}[d T(e(n))+\tau(e(n)) d e(n)] f(n) d n-d p_{S} \cdot s-p_{S} \cdot d s .
$$

Using eqs. (5), (B-11) and (B-13), we obtain

$d R=\int_{\underline{n}}^{\bar{n}}\left[e \cdot g_{M}+\frac{u_{s}}{u_{m}} d s+\tau(e(n)) \frac{\partial M R S_{m s} / \partial n}{\partial M R S_{m e} / \partial n} d s\right] f(n) d n-\left(g_{M}-g_{S}\right) p_{S} s-p_{S} \cdot d s$,

which, after using the modified Samuelson rule (16), becomes

$$
d R=g_{M} \int_{\underline{n}}^{\bar{n}} e f(n) d n-\left(g_{M}-g_{S}\right) p_{S} s>0
$$

where the inequality follows from the fact that $\int_{\underline{n}}^{\bar{n}}$ ef $(n) d n>p_{S} s$. 


\section{References}

Barth, E., K. O. Moene and F. Willumsen, 2014, The Scandinavian model-An interpretation. Journal of Public Economics 117, 60- 72.

Baumol, W.J.,1967, Macroeconomics of Unbalanced Growth: The Anatomy of Urban Crisis, American Economic Review, 57(3), 415-426.

Baumol, W.J.,1993, Health Care, Education and the Cost Disease: A Looming Crisis for Public Choice, Public Choice, 77, 17-28.

Baumol, W.J., and W.G. Bowen, 1966, Performing Arts: The Economic Dilemma, New York: The Twentieth Century.

Baumol, W.J., D. de Ferranti, M. Malach, and A Pablos-Mendez, 2012, The Cost Disease: Why Computers Get Cheaper and Health Care Doesn't, Yale University Press.

Bates, L.J, and R. E Santerre, 2013, Does the U.S. Health Care Sector Suffer from Baumol's Cost Disease? Evidence from the 50 states, Journal of Health Economics, 386-391.

Blomquist, S., V. Christiansen, and L. Micheletto, 2010, Public Provision of Private Goods and Nondistortionary Marginal Tax Rates, American Economic Journal: Economic Policy 2, 1-27.

Boadway, R. and M. Keen, 1993, Public Goods, Self-Selection and Optimal Income Taxation, International Economic Review 34, 463-478.

Christiansen, V., 1981, Evaluation of Public Projects under Optimal Taxation, Review of Economic Studies 48, 447-57.

DREAM, 2014, Produktiviteten i den offentlige sektor, Working paper, March 2014.

European Commission, 2013, Report on Public Finances in the EMU, European Economy 4/2013.

IMF, 2012, The Economics of Health Care Reform in Advanced and Emerging Economies. Jacobs, B., 2013, Marginal Cost of Public Funds is One at the Optimal Tax System, mimeo, Erasmus University Rotterdam.

Jacobs, B. and R. A. de Mooij, 2014, Pigou Meets Mirrlees: On the Irrelevance 
of Tax Distortions for the Second-Best Pigouvian Tax, Journal of Environmental Economics and Management, forthcoming.

Kleven, 2014, How Can Scandinavians Tax So Much? Journal of Economic Perspectives 28(4), 77-98.

Kreiner, C.T. and N. Verdelin, 2012, Optimal Provision of Public Goods: A Synthesis. Scandinavian Journal of Economics, 114, 384-408.

Lindbeck, A., 2006, Sustainable Social Spending, International Tax and Public Finance, 13(4), 303-324.

New Zealand Treasury, 2012, Long-Term Care and Fiscal Sustainability.

Ngai, J.R., and C. Pissarides, 2007, Structural Change in a Multi-Sector Model of Growth, American Economic Review, 91(1), 429-443

Nordhaus, W., 2008, Baumol's Disease: A Macroeconomic Perspective, The B.E. Journal of Macroeconomics - Contributions, 8(1).

Office for Budget Responsibility, 2013, Fiscal Sustainability Report, London.

Regeringen, 2013, Vårpropositionen 2013, Stockholm.

Salanié, B., 2003, The Economics of Taxation, Cambridge, MIT Press.

Slemrod, J. and S. Yitzhaki, 2001, Integrating Expenditure and Tax Decisions: The Marginal Cost of Funds and the Marginal Benefit of Projects, National Tax Journal 54, 189-201.

Sørensen, P. B., 2015, Reforming Public Service Provision: What Have We Learned? EPRU Working Paper 2015-01.

van der Ploeg, F., 2007, Sustainable Social Spending and Stagnant Public Services: Baumol's Cost Disease Revisited, Finanzarchiv, 63(4), 519-547. 